\title{
Multifunctional graphene sensor ensemble as a smart biomonitoring fashion accessory
}

\author{
Vijay Shirhatti, Suresh Nuthalapati ${ }^{1}$, Vaishakh Kedambaimoole ${ }^{1}$, Saurabh Kumar ${ }^{2}$, \\ Mangalore Manjunatha Nayak ${ }^{2}$, Konandur Rajanna ${ }^{1 *}$ \\ ${ }^{1}$ Dept of Instrumentation and Applied Physics, Indian Institute of Science, Bangalore 560012, \\ India \\ ${ }^{2}$ Centre for Nano Science and Engineering, Indian Institute of Science, Bangalore 560012, \\ India \\ Corresponding Author: K Rajanna, Email: kraj@iisc.ac.in
}

\section{S1. Material Characterization}

The physical and chemical properties of the as-synthesized MEGO material were ascertained via different material characterization techniques. The morphology of the MEGO material was examined under the FE-SEM tool, and an exploded form of GO was observed, much like an accordion instrument (figure S1a). This structure is caused due to the intense agitation of the trapped functional groups on the surface of the carbon basal plane during the graphene oxide synthesis process. The graphene oxide is rendered hydrophilic due to the oxidation process and hence readily adsorbs moisture on the surface. The microwave energy vibrates the functional groups and absorbed water molecules, which eventually split the loosely bonded graphene layers apart and escape. This mechanism leads to the accordion structured MEGO. The high magnification SEM image shows few-layer graphene ( $<3 \mathrm{~nm})$ separated from the stack (figure S1b). To further decipher the graphene layers, Atomic Force Microscopy (AFM) was used. The AFM image reveals the presence of monolayer graphene nanosheets in the dispersion of MEGO (figure S1c). The monolayer graphene nanosheet thickness is $\sim 0.8$ $\mathrm{nm}$, agreeing to available reports on the thickness of derived graphene nanosheets. ${ }^{1}$ The thickness of the sensing layer on the IDE is approximated to $\sim 10 \mathrm{~nm}$, extending up to $100 \mathrm{~nm}$ for few stacked or un-exfoliated particles (figure S3).

The graphene nanosheets were examined under Tunnelling Electron Microscope (TEM), and wrinkly graphene sheets were noticed (figure S1d, S1e). The interlayer spacing 
was found to be around $0.39 \mathrm{~nm}$, and the SAED pattern revealed the 6-fold pattern associated with the hexagonal lattice characteristic of the graphene crystalline structure.

a

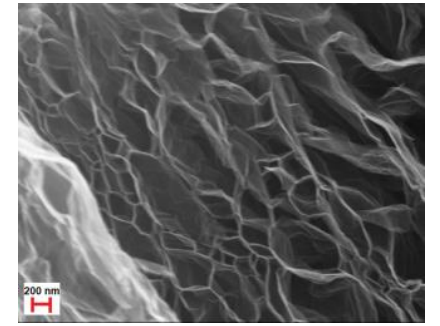

d
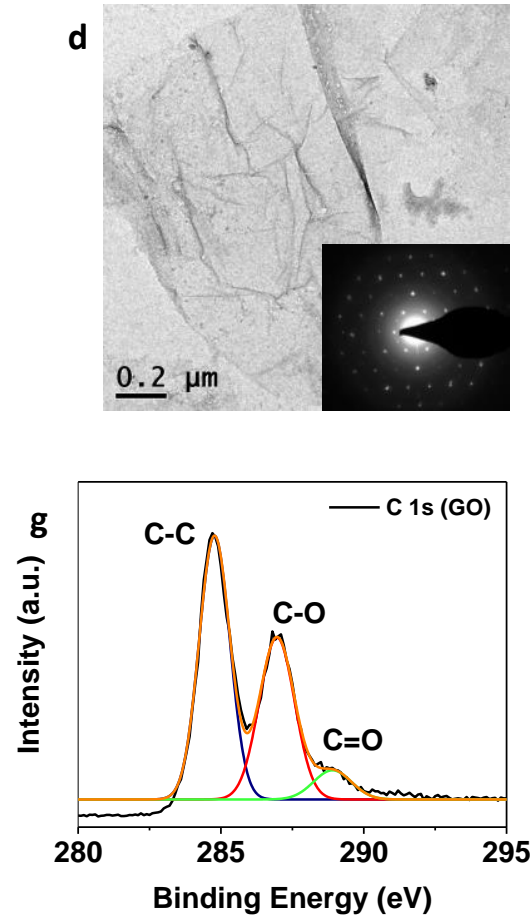

b

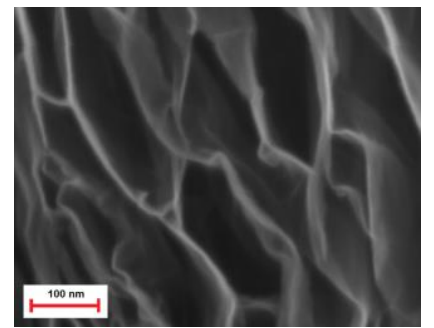

e
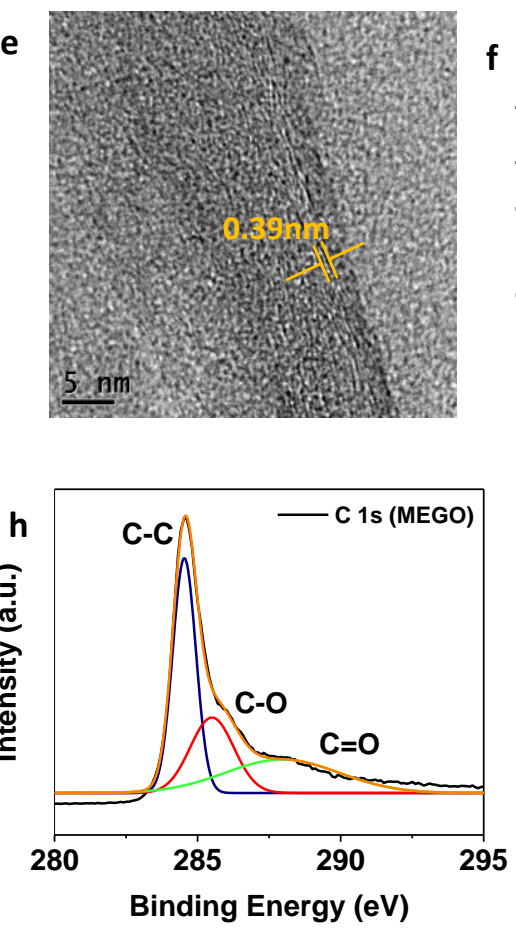

c
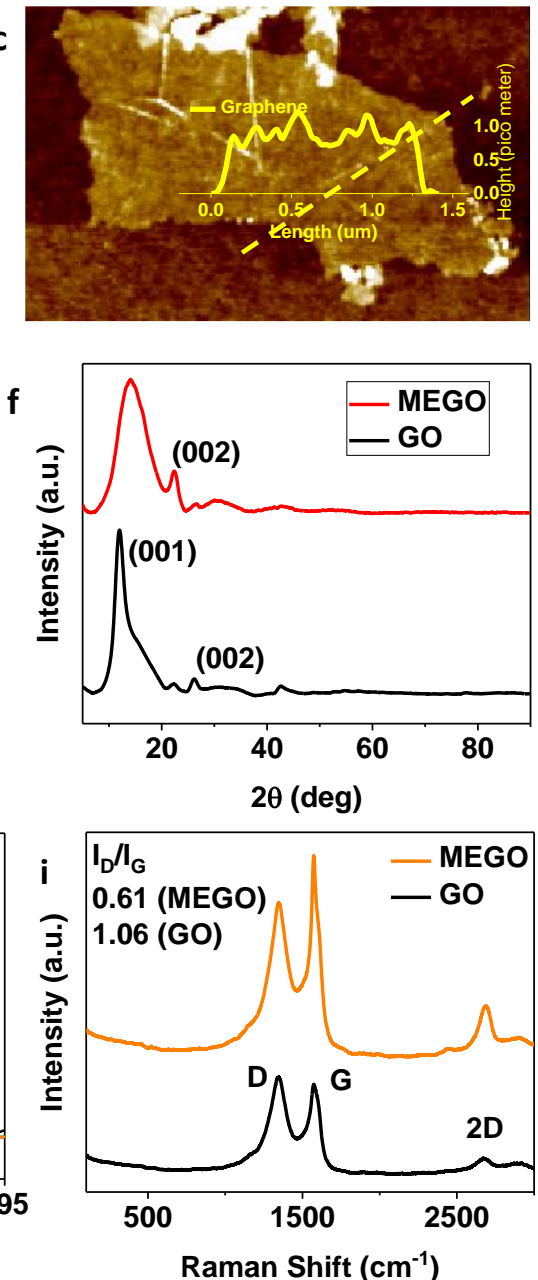

Figure S1. (a) FE-SEM image of MEGO showing the accordion-like structure, (b) high magnification FE-SEM image showing separated graphene sheets with <3nm thickness, (c) AFM image of monolayer graphene sheet with a mean height of $\sim 0.8 \mathrm{~nm}$ and $\sim 3 \mu \mathrm{m}$ lateral dimensions, (d),(e) TEM image of graphene sheets, (inset) graphene SAED pattern, and graphene sheet thickness measured at $\sim 0.39 \mathrm{~nm}$. (f) XRD analysis of GO and MEGO indicating (001) and (002) peaks, revealing reduction of GO after microwave thermal treatment, $(\mathrm{g}),(\mathrm{h})$ XPS analysis of GO showing $1 \mathrm{Cs}$ peak comprising $\mathrm{C}-\mathrm{C}, \mathrm{C}-\mathrm{O}$ and $\mathrm{C}=\mathrm{O}$ bonds, MEGO showing 1Cs peak with lower $\mathrm{C}-\mathrm{O}$ and $\mathrm{C}=\mathrm{O}$ peak intensity due to reduction of GO, (i) Raman spectroscopy of GO and MEGO indicating a reduction in $\mathrm{I}_{\mathrm{d}} / \mathrm{I}_{\mathrm{g}}$ ratio from $\mathrm{GO}$ to MEGO due to removal of functional groups and restoration of defects in the graphene basal plane due to microwave treatment. 
The crystalline structure and the interlayer spacing of the synthesized materials were analyzed via X-Ray Diffraction (XRD) technique. The XRD pattern of GO shows a prominent peak near $11.9^{\circ}$ corresponding to the (001) plane and an interlayer spacing of $0.73 \mathrm{~nm}$ (figure S1f and Table S1). The XRD scan of MEGO revealed a broad peak ((001) plane) at $14.15^{\circ}$, indicating reduction of $\mathrm{GO}$ and removal of the intercalated functional groups. A peak at $22.37^{\circ}$ is observed corresponding to the (002) plane with a higher inter-layer spacing $(0.4 \mathrm{~nm})$ than graphite $(0.34 \mathrm{~nm})$, peculiar of reduced graphene oxide as a result of residual functional groups on the graphene plane. $^{2}$

The X-ray Photo Spectrometry (XPS) measurements definitively confirmed the reduction of GO due to the microwave treatment (figure S1g, S1h). The C1s high-resolution scan of GO indicated prominent $\mathrm{C}-\mathrm{O}$ and $\mathrm{C}=\mathrm{O}$ bonds represented by peaks at $286.93 \mathrm{eV}$ and $288.92 \mathrm{eV}$, respectively, along with the dominant $\mathrm{C}-\mathrm{C}$ peak at $284.6 \mathrm{eV}$. On the other hand, MEGO $\mathrm{C} 1 \mathrm{~s}$ high-resolution scan revealed reduced peak intensity of $\mathrm{C}-\mathrm{O}$ and $\mathrm{C}=\mathrm{O}$ bonds leading to the above inference.

The vibrational modes of the MEGO were observed in the Raman spectroscopy(figure S1i). It was deduced that the removal of functional groups from the basal graphene plane due to microwave treatment resulted in the restoration of the defect sites. The $\mathrm{I}_{\mathrm{D}} / \mathrm{I}_{\mathrm{G}}$ ratio in MEGO was lower than that in GO, which led to the above conclusion.

The peculiar morphology of MEGO also warranted characterizing the material for its total surface area. The MEGO material was significantly higher in volume than the GO and extremely light in weight such that a mild air draft could blow its particles. The surface area of the MEGO was examined via N2 gas absorption and BET analysis. The material was found to have a total surface area of $351.1 \mathrm{~m}^{2} / \mathrm{g}$ (figure S2).

\section{S2. XRD FWHM, Crystallite size and Interlayer spacing}

Table S1: Crystallite size and Interlayer spacing in GO and MEGO material

\begin{tabular}{|l|r|r|r|r|}
\hline & \multicolumn{1}{|l|}{$\begin{array}{l}\text { 2Theta } \\
(\mathbf{d e g})\end{array}$} & FWHM & $\begin{array}{l}\text { Crystallite Size } \\
(\mathbf{n m})\end{array}$ & $\begin{array}{l}\text { Interlayer } \\
\text { spacing (nm) }\end{array}$ \\
\hline GO & 11.99 & 1.86714 & 4.278187571 & 0.737253595 \\
\hline & 14.42 & 6.55675 & 1.221276802 & 0.613514587 \\
\hline & 22.36 & 2.2074 & 3.668553472 & 0.397128459 \\
\hline
\end{tabular}




\begin{tabular}{|l|l|l|l|l|} 
& 26.17 & 1.68818 & 4.831273247 & 0.340111545 \\
\hline MEGO & 13.22 & 4.23969 & 1.886329082 & 0.668922325 \\
\hline & 15.28 & 6.44109 & 1.244423283 & 0.579172257 \\
\hline & 22.37 & 1.55599 & 5.204470875 & 0.396953191 \\
\hline & 26.68 & - & & 0.333724719 \\
\hline
\end{tabular}

\section{S3. BET Analysis}

[5.3.2.0] Belsorp Adsorption/Desorption Data Analysis Software

BEL Japan, Inc.

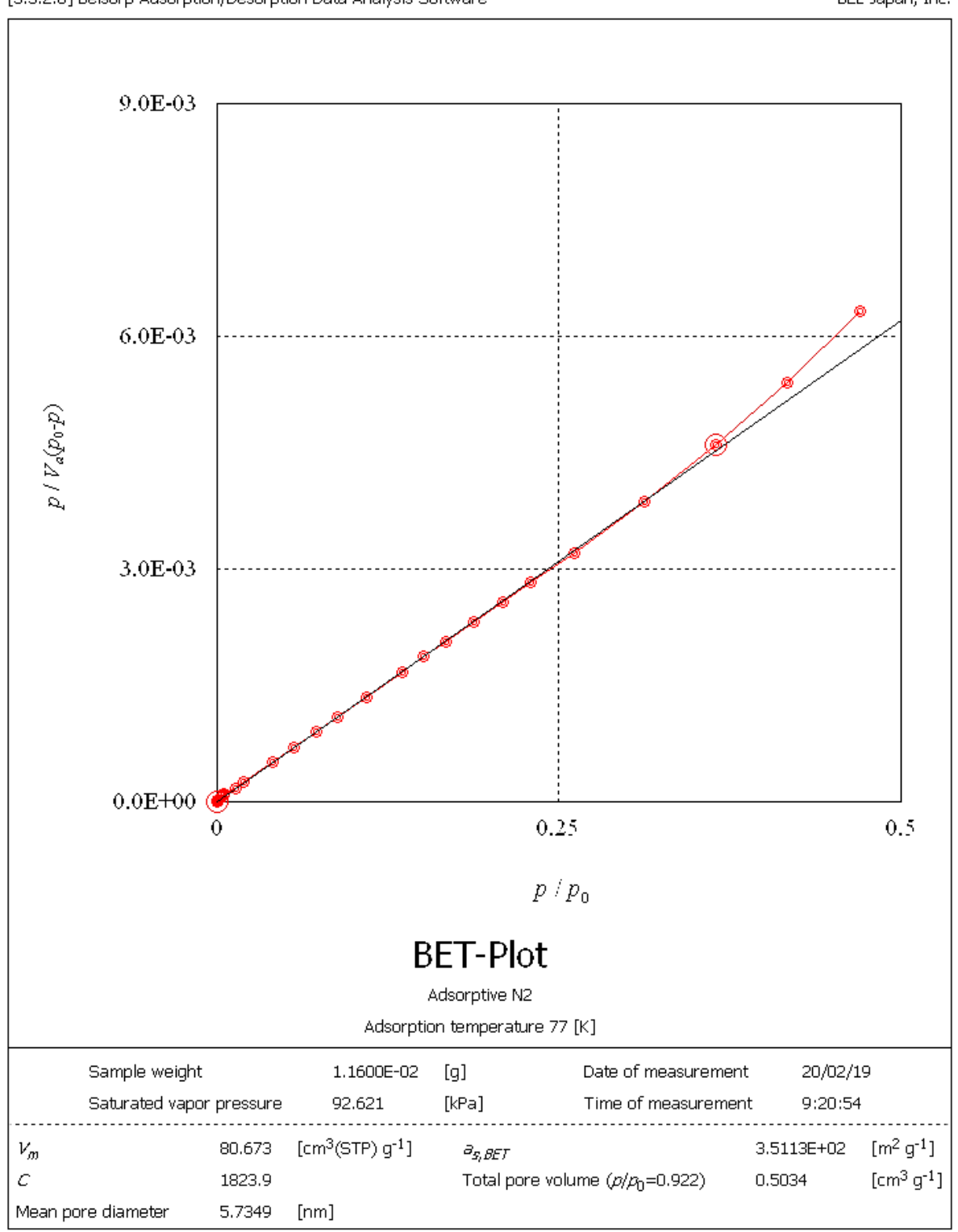

Figure S2. BET analysis of MEGO material, surface area $351 \mathrm{~m}^{2} / \mathrm{g}$. 


\section{S4. AFM}
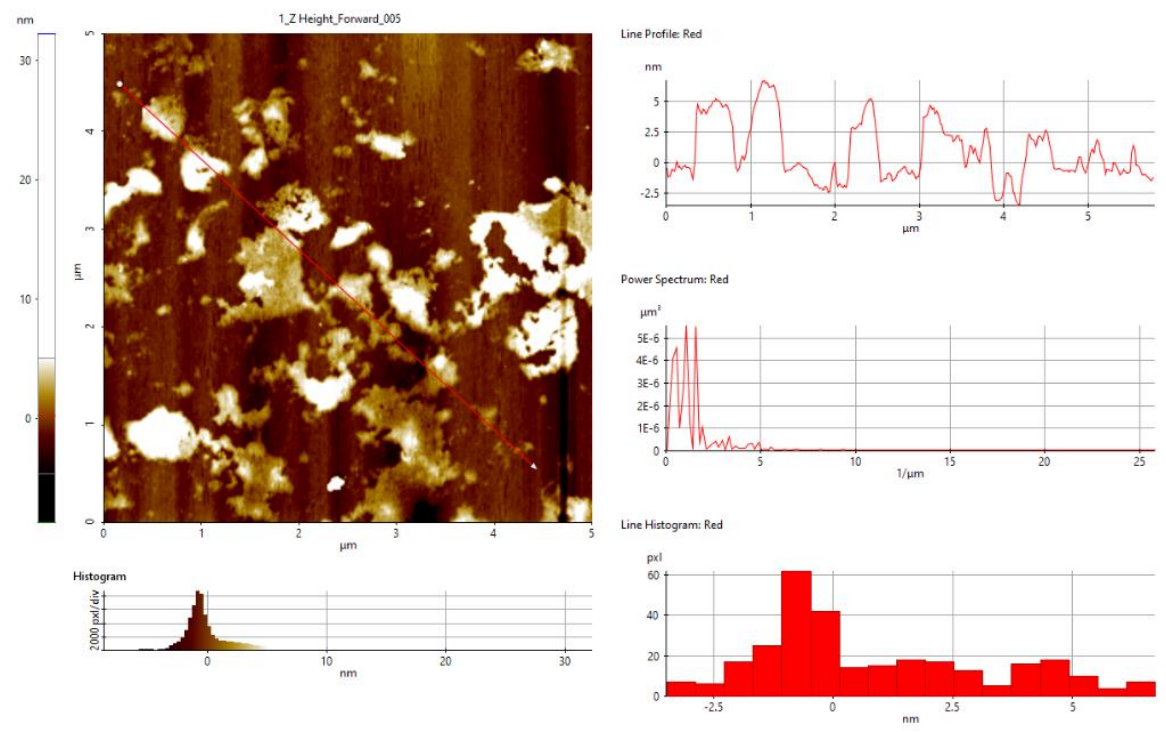

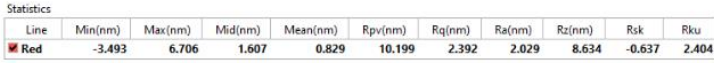

Figure S3. Atomic force microscopy of randomly distributed graphene nanosheets on silicon substrate. Max Height $\sim 6.7 \mathrm{~nm}$ 


\section{S5. Profilometer analysis}
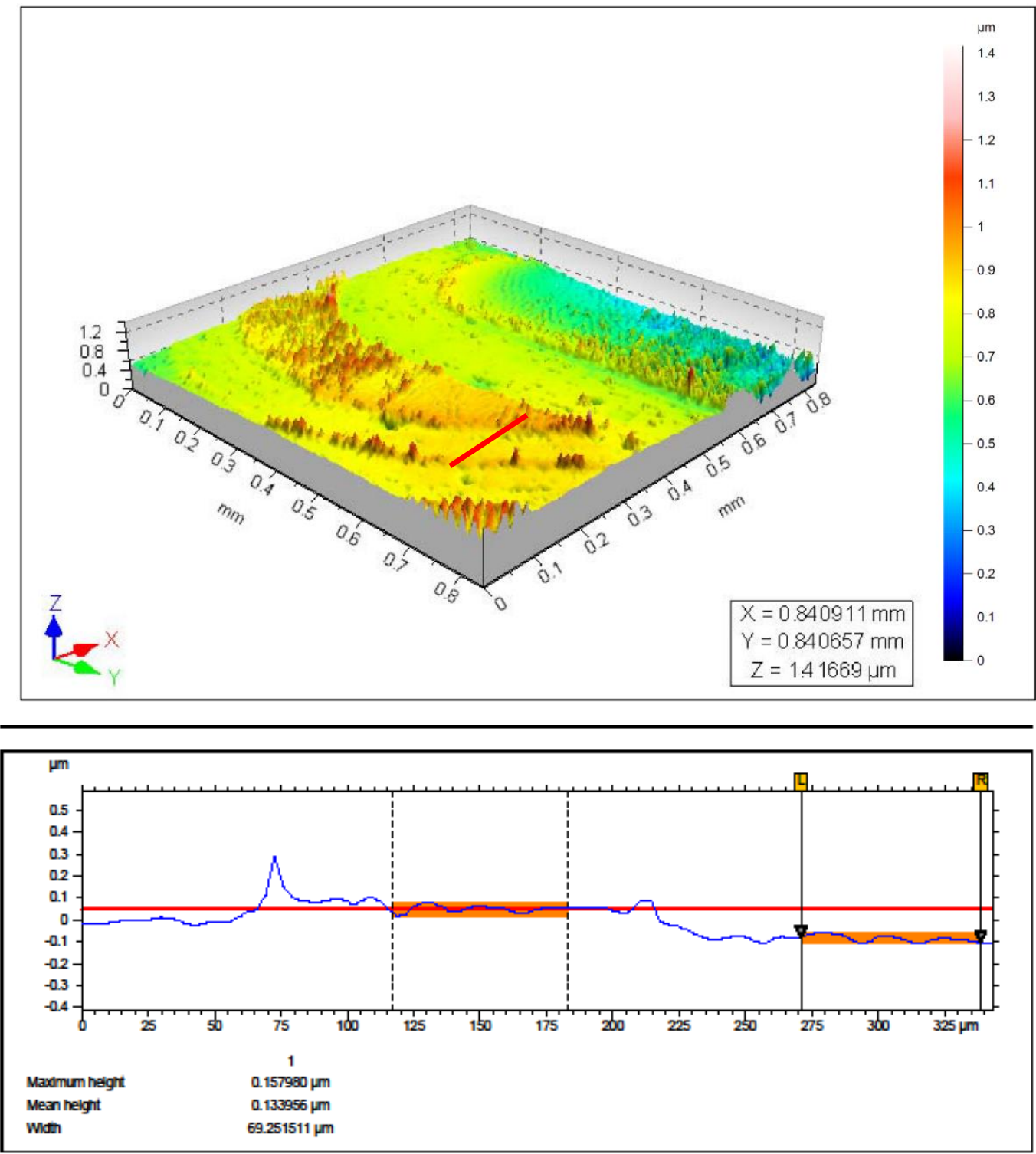

Figure S4. Optical profilometer imaging of IDE on PDMS substrate, mean depth after etching $133 \mathrm{~nm}$ 


\section{S6. Choice of Chromium-Gold Thin film stack}

The GLE sensor electrodes were realized by laser-patterning of Chromium - Gold thinfilm. The choice of Gold as the metal thin-film is the based on the properties of Gold found superior to that other metal thin-films, ${ }^{3}$ viz.

- Gold $(\mathrm{Au})$ is chemically stable in ambient conditions, i.e. gold does not form an oxide layer in air and hence reliable electrical contacts are possible.

- It has very good electrical conductivity - electrical resistivity of gold is one of the best, only behind silver and copper, which are prone to corrosion and wear.

- Gold forms an ohmic contact with graphene ensuring that there is no rectification and loss of valuable sensor signal. ${ }^{4}$

- Gold is bio-compatible i.e., it does not react to bodily fluids and is non-toxic.

- Gold has a lustrous appearance and globally accepted as an element of choice for ornamental accessories,

The use of Chromium to form a stacked thin-film layer is primarily focussed towards providing an improved adhesion of the thin-film stack. As reported in literature, ${ }^{5} \mathrm{Cr}$ metal provides good adhesion to different substrates, and with other metal thin-films. The Cr thinfilm acts as the adhesion layer between Gold and the PDMS/PET substrate, and the stacked layer showed satisfactory adhesion to the substrate ensuring efficient performance toward demonstrated applications.

\section{S7. Advantage of Laser-Etch patterning method over existing fabrication techniques for nanomaterials-based sensors.}

While there are several studies reported on inkjet printing and direct printing techniques, ${ }^{6-9}$ there are prominent differences in the fabrication techniques reported in these studies with the currently reported Laser-etch patterning method. An important aspect discussed in all these studies is the rheology of the synthesis graphene ink. The additive manufacturing technology involved in getting the perfect graphene ink requires intensive study and holds vital role in the above techniques.

The graphene nanosheet ink reported in the current work is found to be simple and customizable. The NMP surfactant used for dispersing MEGO acts as a carrier for graphene nanosheets and can be replaced with other surfactants like DMF, Acetone without much impact 
on the functionality of the ink. The factor that the ink is drop-casted and nanosheets are randomly arranged on the sensor relieves of the facet that a uniform graphene layer is required, as in the case of previously reported studies. The printing techniques discussed above primarily use graphene-based inks for printing the IDEs or sensing elements. When the electrodes of a capacitor or the sensing element is printed using graphene ink, numerous challenges such as discontinuous lines, short between the electrodes, over-spraying, lack of adhesion to the substrate and peeling film, change in viscosity of the ink, difficulty in drawing electrical contacts among many other issues.

In the current work, the electrodes are realized in the $\mathrm{Cr}$-Au thin-film using fast Laserpatterning technique. The thin-film deposition technology is an established and well-studied field, leading to uniform, repeatable and consistent thin-films via techniques such as sputtering and thermal evaporation. The obtained thin-film is then patterned using Laser-etching process which further eliminated the use of mechanical masks and its related challenges such as high critical dimension, low-resolution and misalignment. The use of -metal thin film as electrodes has provided an opportunity to use the simple yet effective, drop-casting method for depositing graphene ink, where factors such as discontinuity, shorting, adhesion \& peeling, over-spraying and difficulty in drawing electrical contacts are eliminated. Another feature of the developed fabrication process is that the amount of graphene required for a GLE sensor is very low, considering that only few layer nanosheets are dispersed on that circular IDE (approximated to less than $5 \mu \mathrm{g}$ ). Whereas reported fabrication procedures discussed in literature require large quantities of graphene material for realizing thick milli-meter scale IDE electrodes and sensing layers. A minimum quantity of graphene ink is required to obtain efficient inkjet spray printing, where most of this ink is wasted to over-spraying and sticking to the parts of the equipment.

It has been observed that sensing layers obtained by methods such as inkjet printing often have thickness of few micro-meters, as summarized in table S2. This approach leads to lower sensitivity and resolution of the sensor. It has been discussed at stretch the importance of thin nano-meter scale sensor thickness to achieve high low-pressure sensitivity and resolution. 


\section{S8. Experimental setup}

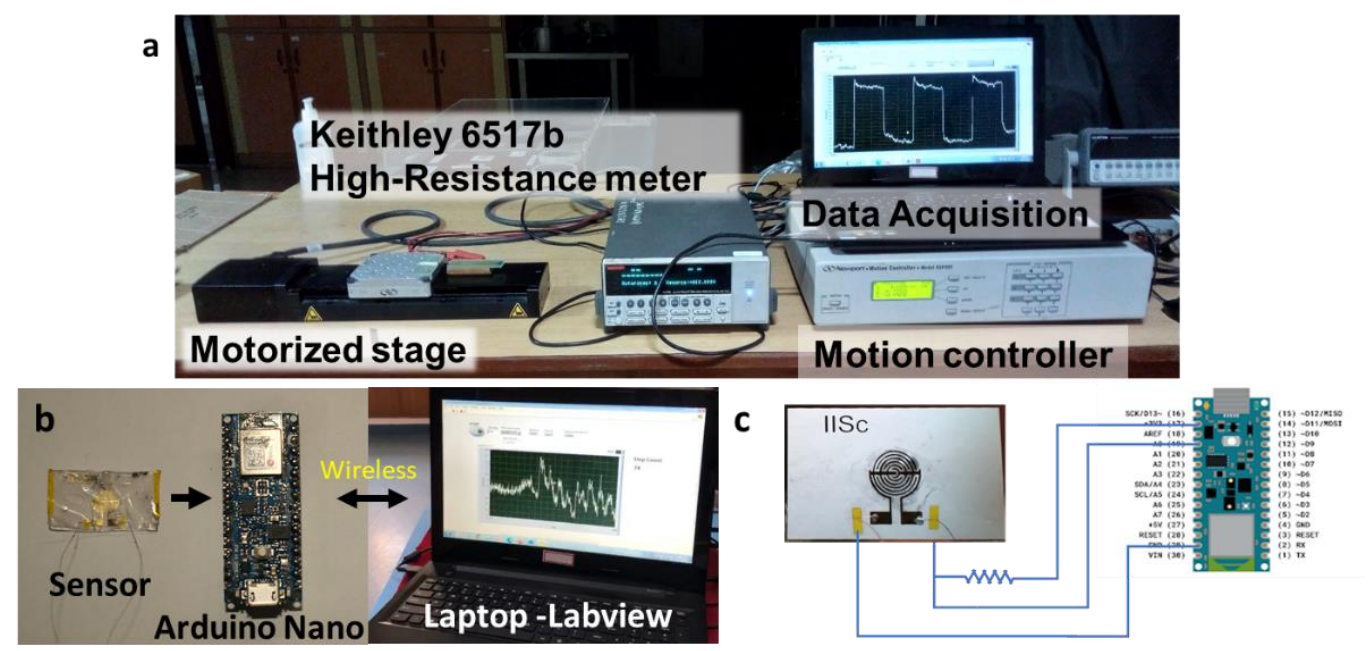

Figure S5. (a)Mechanical Characterization - Resistance measurement via Keithley 6517B, (b) Wireless transmission of sensor signal via Arduino nano BLE, (c) voltage divider circuit for sensor signal measurement.

All sensor characterization experiments have been carried out using Keithley Highresistance meter (6517B), interfaced using LabVIEW software, and involved measurement of the sensor resistance. The biomedical experiments involving movement of the subject were carried out by employing Arduino Nano IOT board, which helped in enabling mobility of the subject by the feature of wireless data transmission. Experiments such as Pedometer (step counting), Pulse measurement, Control input, Limb movement and Body temperature applications were carried out using this setup. Since the board includes Analog input channels that only accept voltage measurements, the sensor was connected in a voltage divider circuit and the sensor resistance was measured as voltage drop across it. Moreover, since all modern wearable test boards accept voltage measurements, this demonstration helped in projecting a practical application of the developed GLE Wearable sensor. 


\section{S9. COMSOL Simulation}
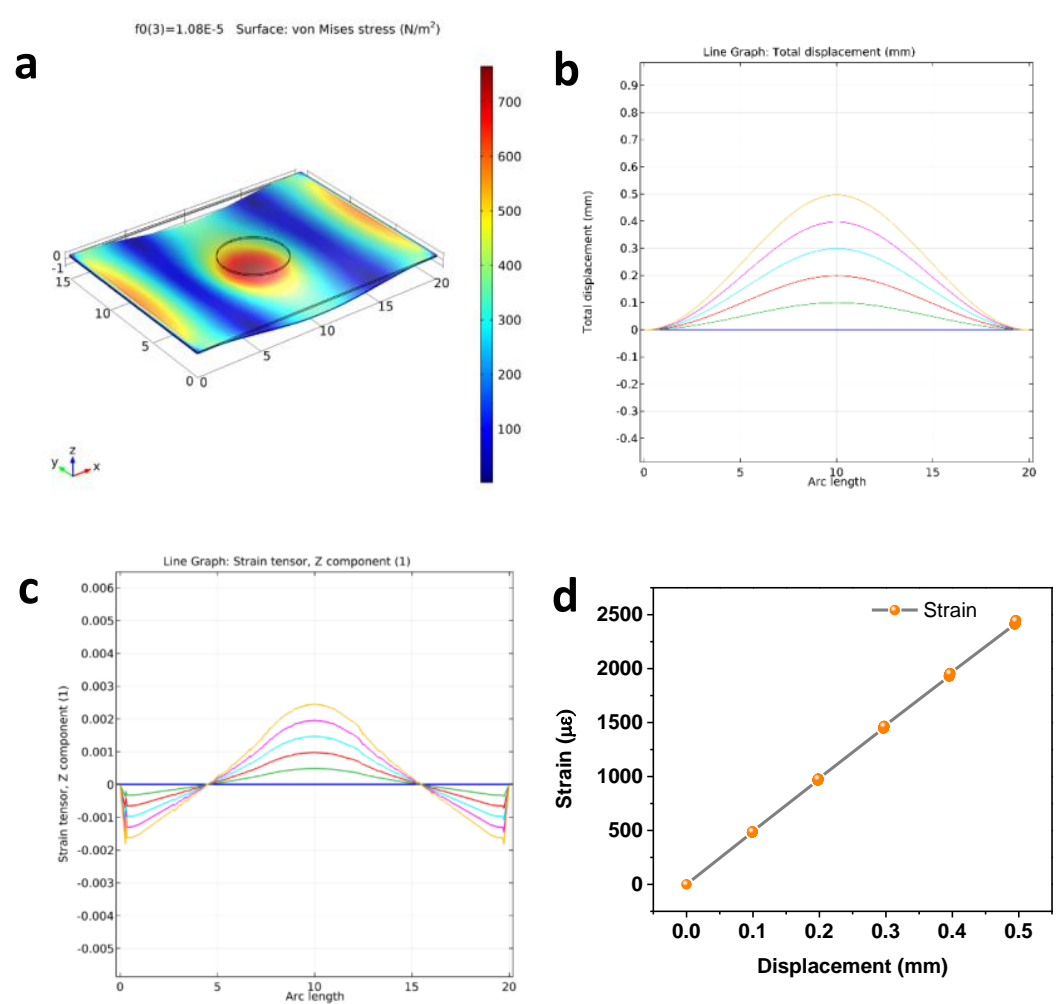

Figure S6. COMSOL Multiphysics simulation for deriving strain induced in GLE sensor for known deflections. (a) Strain distribution of sensor surface, (b) sensor displacement along the length, (c) strain along the sensor median, (d) relation of strain to induced displacement.

\section{S10. Repeatability Tests and Transient Response}

The figure 7a shows GLE sensors from 10 batches, followed by response of some of the sensors (figure 7b-g). The repeatability of GLE sensor shown is shown in figures 8a-c. The transient response of the GLE sensor was studied by inducing rapid deflection (figure 8d-e). The sensor was deflected for $0.2 \mathrm{~mm}$ at a speed of $5 \mathrm{~mm} / \mathrm{s}$. The sensor's rise time was found to be $54 \mathrm{~ms}$ for an input rise time of $40 \mathrm{~ms}$, and the fall time of the sensor was found to be $52 \mathrm{~ms}$ for a similar input fall time. 
a
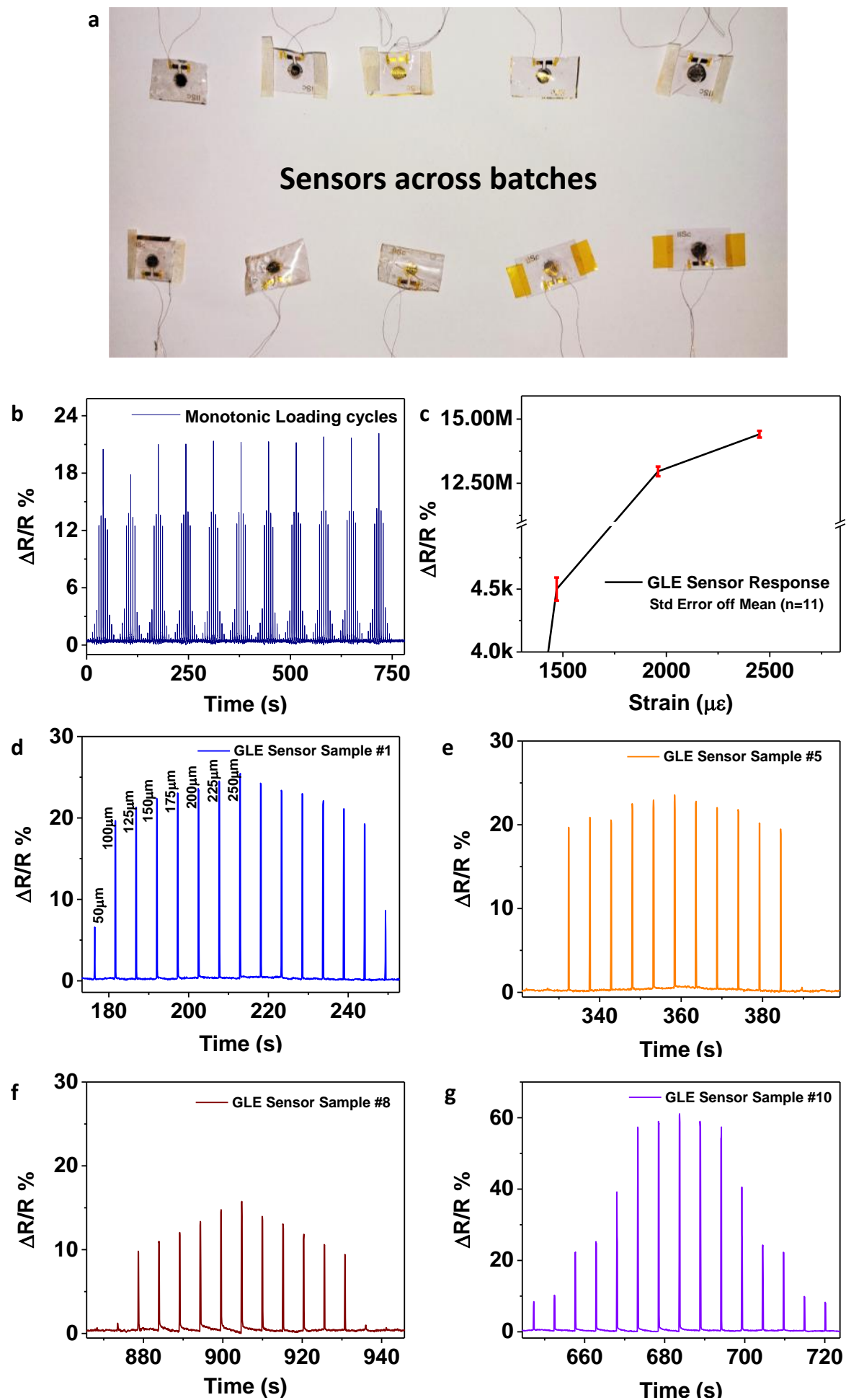

Figure S7. (a) Image of 10 GLE sensors fabricated across batches, (b) Cycles of Monotonic Loading of GLE sensors showing consistent response, (c) GLE sensor response over repeated cycles with error bars at high strain range, $(\mathrm{d})-(\mathrm{g})$ Monotonic loading cycles for samples - \#1, \#5, \#8, \#10, 

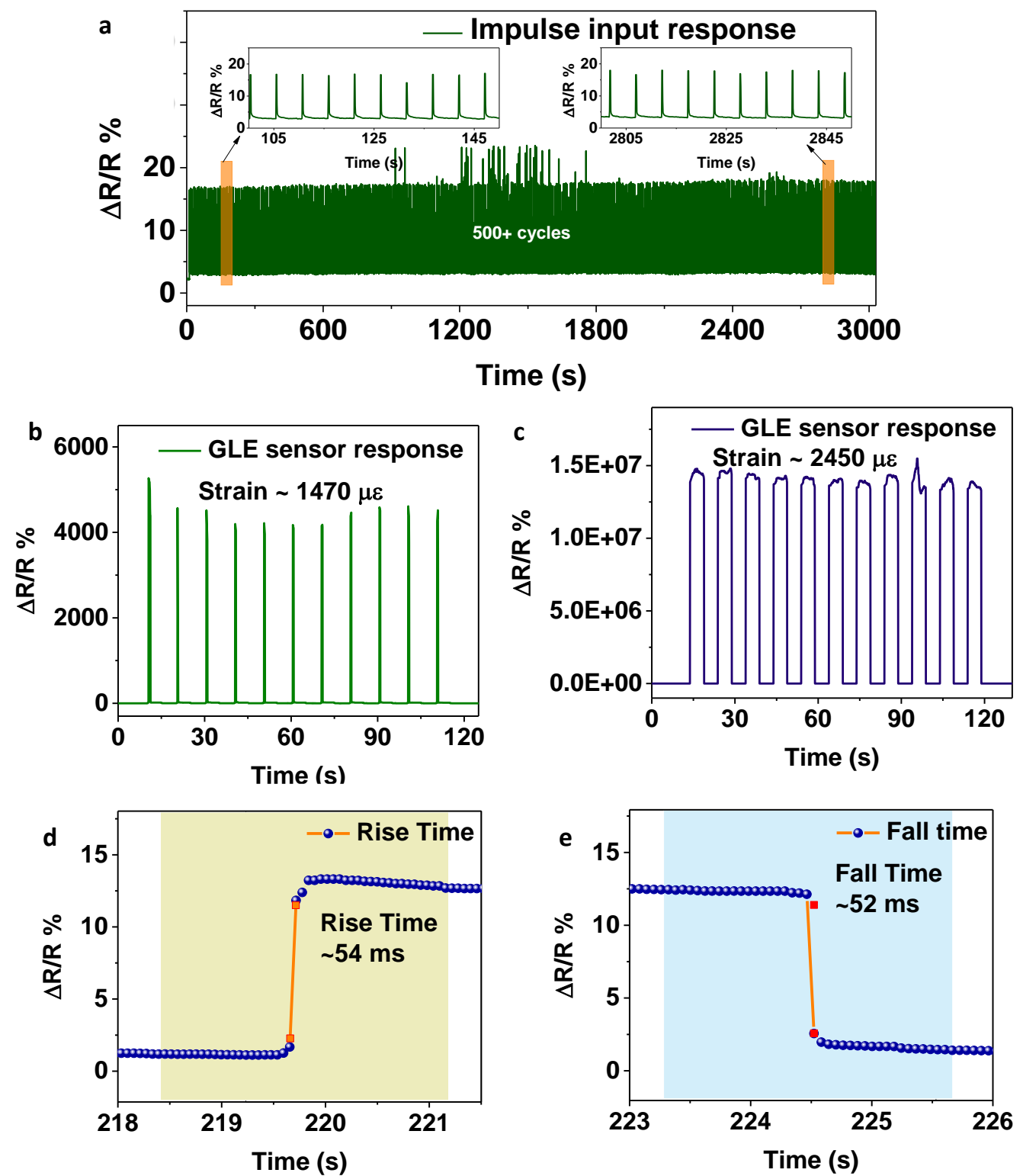

Figure S8. (a) Plots showing repeatability of GLE sensor for cyclic loading- Impulse/tapping mechanical input, (b) Multiple impulse input cycles at high strain input 1470 ue (GF 4000), (c) Multiple cycles at 2450 ue (GF - 6e7), (d) GLE sensor transient response- rise time (54 $\mathrm{ms})$ and (e) fall time (52 ms), 


\section{S11. Gold thin-film strain response}

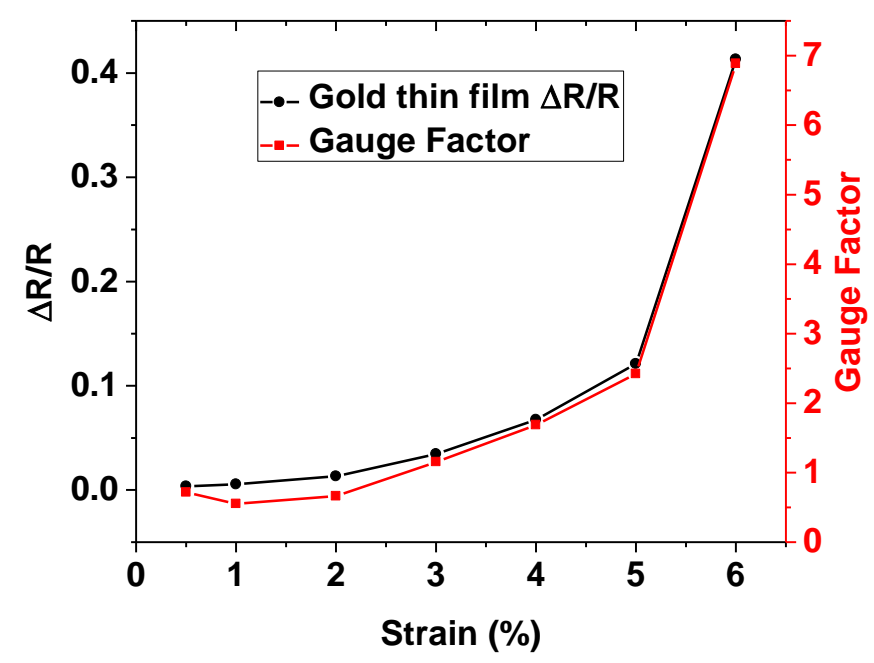

Figure S9. Response of Gold thin film to applied strain and corresponding gauge factor

\section{S12. Derivation of Equations to substantiate GLE sensor Sensing Mechanism.}

Similar equations have been adopted in the literature to explain the above hypothesis. Zhang et al., 2000 for conductor with filler polymers and Souri et al., 2020, for nanomaterialbased sensors have presented similar models for sensing mechanism in percolative networks based sensors. $^{10,11}$ As explained by Zhang et al., 2000, the resistance of the sensing layer can be put forth as equation $\mathrm{S} 1$,

$$
R=\frac{G\left(R_{S}+R_{c}\right)}{P}
$$

where,

$\mathrm{G}$ and $\mathrm{P}$ are defined as above,

Rs is the graphene sheet resistance, considered constant in the above case,

$\mathrm{Rc}$ is the contact resistance between the adjacent graphene sheets.

$$
R=\frac{G \cdot R_{s}+G .^{\rho L} / A_{c}}{P}
$$

Where, $\rho, L$ are resistivity of the graphene sheets and width of the sheets.

$$
R=\frac{G \cdot R_{s}}{P}+\frac{G \cdot \rho L}{P \cdot A_{c}}
$$

In the above equation, $R s, \rho, L$ are considered constants, which leads to the equation $\mathrm{S} 2$ stated below. 


$$
\Delta R \propto \frac{G}{P} \cdot \frac{1}{A_{c}}
$$

... Equation S2

where $\mathrm{R}$ is the resistance of the sensing film,

$\mathrm{G}$ is the number of graphene nanosheets forming a single conduction path,

$\mathrm{P}$ is the number of parallel conductive paths established between the two electrodes,

Ac is the cumulative contact area between the graphene nanosheets in the network.

The equation governing change in resistance due to tunnelling mechanism is given as follows.

The resistance of the sensing film can be expressed as equation S3, shown below.

$$
R=\frac{G}{P}\left[\frac{8 \pi h d}{3 A_{t} \gamma e^{2}} \cdot \exp (\gamma d)\right]
$$

where, G and P hold the same notations as above,

$\mathrm{h}$ is the Planck's constant,

$\mathrm{e}$ is the electron charge,

At is the effective area concerning the occurrence of tunnelling,

$\gamma=\frac{4 \pi}{h}(2 m \varphi)^{1 / 2} \quad$, where $m$ is the electron mass, and $\varphi$ is the potential barrier

between the two conducting particles,

$\mathrm{d}$ is the distance between the adjacent graphene sheets.

The above equation can be simplified to the proportionality equation $\mathrm{S} 4$, since all other terms are approximated as constants,

$$
R \propto \frac{G}{P} \cdot \exp (\gamma d)
$$

... Equation S4

Therefore, the sensor resistance varies exponentially with the increasing distance between the adjacent graphene sheets, as seen from the sensor response. 


\section{S13. Study on Strain-dependence of PET based GLE sensor}

The GLE sensor for temperature measurement was fabricated on a PET substrate $(\rho=$ $1390 \mathrm{~kg} / \mathrm{m}^{3}$, thermal conductivity@ $23^{\circ} \mathrm{C}=0.14 \mathrm{~W} / \mathrm{m} . \mathrm{K}$, Specific heat capacity $\left(\mathrm{c}_{\mathrm{p}}\right)=1.27$ $\mathrm{kJ} / \mathrm{kg} . \mathrm{K}$, tensile strength $=70 \mathrm{MPa})$ and covered with a PDMS coating layer $\left(\rho=970 \mathrm{~kg} / \mathrm{m}^{3}\right.$, thermal conductivity @ $23^{\circ} \mathrm{C}=0.15 \mathrm{~W} / \mathrm{m} . \mathrm{K}$, Specific heat capacity $\left(\mathrm{c}_{\mathrm{p}}\right)=1.46 \mathrm{~kJ} / \mathrm{kg} . \mathrm{K}$, tensile strength $=2.24 \mathrm{MPa}$ ). The higher strength of the PET substrate minimized the strain-dependent response of the sensor as compared to PDMS substrate GLE. The PET substrate use ensured that the small mechanical deformation of the sensor did not affect the sensor response. The use of PDMS for temperature sensor was deemed unfit since small un-intended deformations induced in the sensor resulted in a considerable change in the response. The PET substrate was found to be insensitive to small mechanical deformations based on experiments carried out on GLE sensor fabricated on PET substrate (figure 1i of manuscript). The GLE sensor (PET) was found to show no discernible response to tapping forces as compared to the GLE sensor (PDMS) and a comparative graph (figure S10a) evidently shows the same. The sensor was further subjected to bend to bending force and a bending angle of $135^{\circ}$ resulted in small deviations in the sensor response (figure S10b). Evidently it can be deduced that since such bending forces will not be experienced in a band / bracelet form, it is stated that PET substrate ensured insensitivity to mechanical deformations. This response was effectively used in temperature measurements, which is not affected by application of pressure / strain.
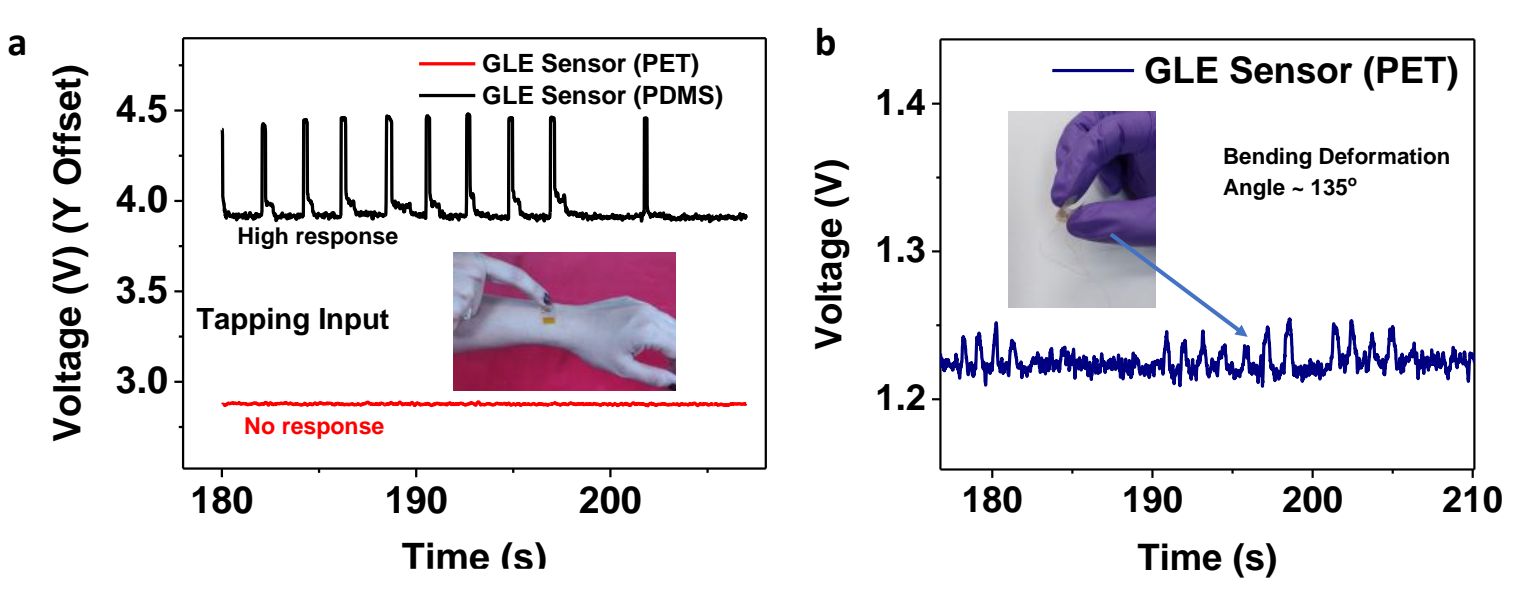

Figure S10. (a) GLE sensor on PET showing no response to tapping type mechanical deformation, (b) GLE sensor on PET showing response to deformations after $135^{\circ}$ bending. 


\section{S14. Bracelet fabrication}

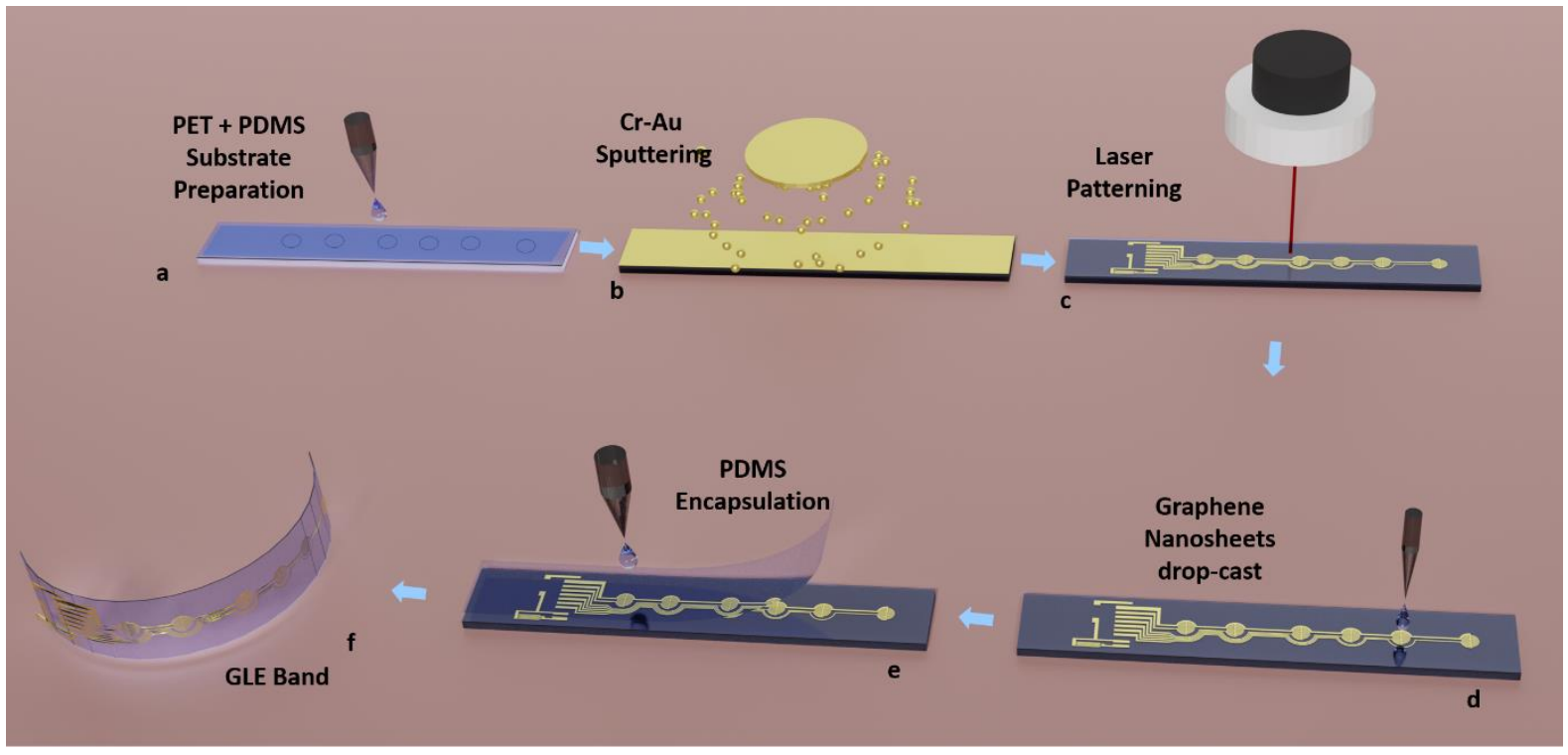

Figure S11. Fabrication of multi-sensor GLE bracelet. (a) PDMS spin-coated on PET substrate with through holes at specific locations, supported by PMMA strip, (b) Deposition of $\mathrm{Cr}-\mathrm{Au}$ thin-film on PDMS via RF sputtering process, (c) Laser-patterning of the top thin-film layer to form GLE Band pattern, exposing PDMS under-layer, (d) drawing electrical contacts and dropcasting GLE ink on the IDE, (e) encapsulation with top PDMS layer, (f) GLE Band peeled off from the substrate.

\section{S15. Discussion on Cross-sensitivity in the GLE Band}

The challenging aspect of the GLE Band design is that different sensors in the band will have cross-sensitivity, i.e., sensors meant for control inputs may detect wrist movement and sensor for pulse rate detection may detect wrist movement or control inputs. All the given sensors may even drift with respect to temperature. The hydration sensor is only a pair of electrodes patterned on the band for measuring skin resistance and expected to have least crosssensitivity. There can be different combinations of cross-sensitivity and same is inherent to the design of the GLE Band.

However, sufficient measures have been taken to minimize this cross-sensitivity by means of design and selection of substrate material, appropriate placement of the sensors, and opportunity for signal compensation via data processing algorithms. The design of the GLE band highlighting the substrate structure is shown in figure 5a of manuscript. The design shows that the GLE band has Polyethylene substrate as the load bearing substrate, with through holes 
in the region of the GLE sensors. The GLE sensors are realized on PDMS substrate for ensuring maximum flexibility and stretchability. The mechanical characterization of GLE sensor on PDMS substrate has been discussed in length in the above section, (figure 2), and insensitivity of GLE sensor on PET substrate has been discussed in figure S10. Therefore, the presence of PE layer in the GLE band sandwich ensures that, forces on one sensor are not propagated to other sensor, such as, input on one control input sensor/button does not trigger the adjoining control input. Further, the temperature sensor design is modified to linear comb type IDE and realized on the PET substrate. The temperature sensor therefore is insensitive to the mechanical deformations and can provide accurate body temperature reading. Moreover, the obtained temperature reading can be applied towards run-time temperature compensation in other strain/pressure GLE sensors in the band which may be affected by the temperature drift.

The position of the sensors is designed such that maximum strain pressure is experienced by the concerned GLE sensor and not by adjoining sensors (figure S12). For instance, the GLE sensor for pulse detection is placed near the radial artery where pulse can be efficiently detected but forces from control input button sensors is not transferred to this sensor. The sensors for wrist movement detection are placed on the sides of the wrist to detect wrist movement and the control input sensors on the top surface of wrist where human interfacing can be easily achieved. The temperature sensor is placed on the underside of the wrist, where the arteries are close to the epidermis, for accurate temperature measurement. The hydration sensor is also placed on the underside of the wrist where effect of strain on the skin due to control input/motion is minimum.

Furthermore, the demonstrated applications largely depend on pattern recognition where absolute value of the sensor has minimal bearing on the obtained measurements (barring temperature sensor, where accurate calibration is required, and ensured from the sensor design). The application provides for an excellent opportunity for machine algorithms (such as rolling window algorithm used for all the demonstrated experiments) for efficient pattern recognition and useful information from the obtained signal. 

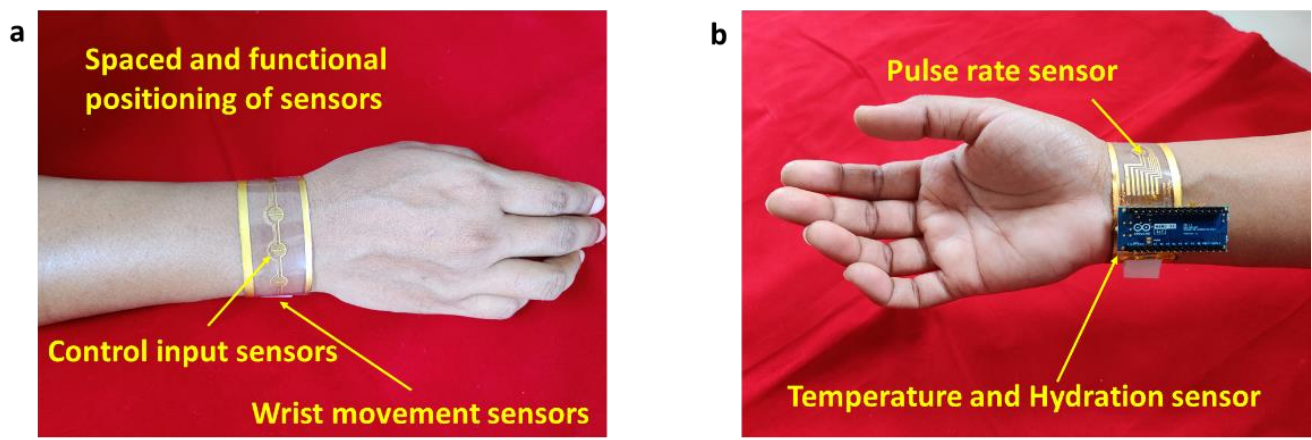

Figure S12. (a)(b) images depicting spaced and functional positioning all sensors in the GLE band.

\section{S16. GLE Band Wearing Comfort}

The developed GLE Band / Bracelet was fastened on the wrist of the subject using 'hook and loop' fastening tape of dimension 1 x $2 \mathrm{~cm}$, (hook and loop attached to either side of the band). The 'hook \& loop' were positioned at the back of the wrist, and the positions of the sensors in the band were such that they aligned with their respective functionality. The band was hand tightened only to the extent that it adhered to the skin and did not apply pressure on the wrist of the subject, while the 'hook \& loop' ensured that the device is immobilized on the skin. The band was easy to wear and remove from the wrist with the help of this fastening technique. The GLE band was comfortable, light in weight and was analogous to wearing a wrist-watch / fitness tracker. The biocompatibility of the substrate ensured that the subject's skin was not irritated on contact with the band even for longer duration. 


\section{S17. Bracelet designs}

a

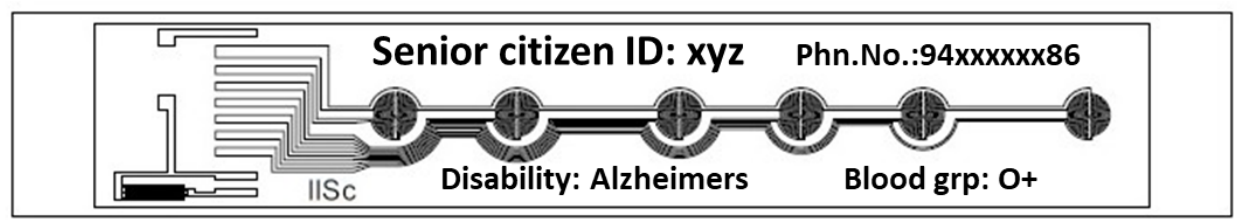

b

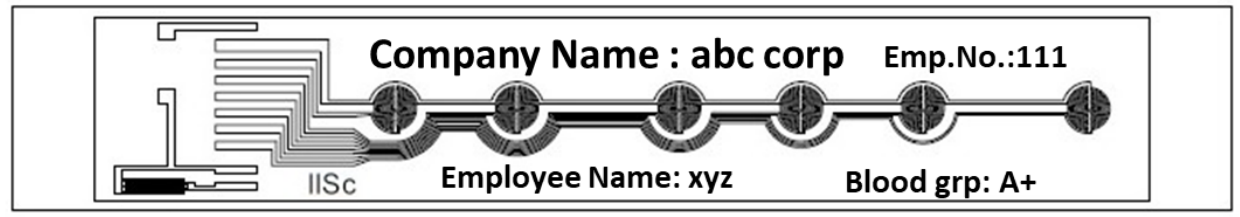

C

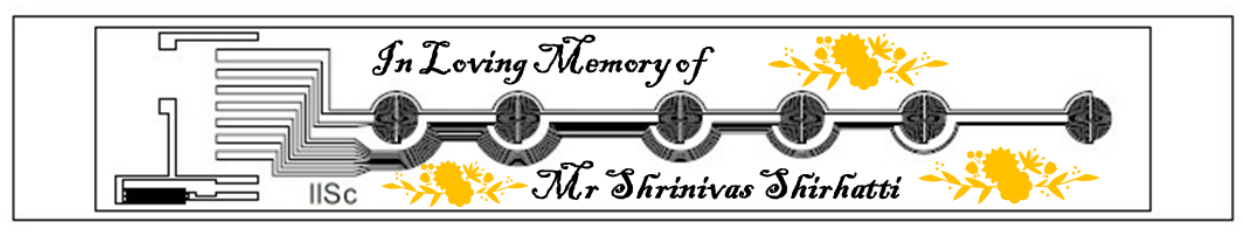

Figure S13. Sample designs for GLE Bracelet/Band with varied objectives, (a) Band for senior citizens with important personal details, (b) corporate band with employee details and security QR code, (c) Personalized Memorabilia. 


\section{S18. Comparison Table}

Table S2: Comparison of few wearable devices reported in the literature with the currently presented work.

\begin{tabular}{|c|c|c|c|c|c|c|}
\hline Material & $\begin{array}{l}\text { Method of } \\
\text { fabrication }\end{array}$ & Sensitivity/GF & $\begin{array}{l}\text { Sensing layer } \\
\text { Thickness }\end{array}$ & Appearance & Multifunctional & Reference \\
\hline $\begin{array}{l}\text { Graphene } \\
\text { nanosheets }\end{array}$ & $\begin{array}{l}\text { Drop cast on } \\
\text { circular IDE }\end{array}$ & $6.38 \mathrm{E}+07$ & $\begin{array}{l}\sim 10 \mathrm{~nm} \\
\text { (up to } 100 \mathrm{~nm} \text { ) }\end{array}$ & $\begin{array}{l}\text { Transparent } \\
\text { layer, Gold } \\
\text { pattern }\end{array}$ & Yes & $\begin{array}{l}\text { This } \\
\text { work }\end{array}$ \\
\hline $\begin{array}{l}\text { Hollow tubing } \\
\text { graphene fibers }\end{array}$ & $\begin{array}{l}\text { CVD graphene } \\
\text { with PDMS }\end{array}$ & 48.9 & & Dark strand & No & 12 \\
\hline $\begin{array}{l}\text { Graphene } \\
\text { Aerogel }\end{array}$ & $\begin{array}{l}\text { Vacuum } \\
\text { Freeze drying }\end{array}$ & 159 & $1 \mathrm{~cm} 3$ & $\begin{array}{l}\text { Dark } \\
\text { Sponge }\end{array}$ & No & 13 \\
\hline $\begin{array}{l}\text { Graphene } \\
\text { membrane }\end{array}$ & Air drying & $52.3 \mathrm{kPa}-1$ & $10 \mathrm{um}$ & Dark Patch & No & 14 \\
\hline rGO & $\begin{array}{l}\text { Ecoflex filled } \\
\text { with rGO ink }\end{array}$ & 31.6 & & $\begin{array}{l}\text { Dark } \\
\text { channel in } \\
\text { rubber }\end{array}$ & No & 15 \\
\hline $\begin{array}{l}\text { Gold } \\
\text { nanoparticles }\end{array}$ & $\begin{array}{l}\text { Gold sputter } \\
\text { coating on } \\
\text { PDMS }\end{array}$ & 5888.89 & $50 \mathrm{~nm}$ & Gold layer & No & 16 \\
\hline $\begin{array}{l}\text { PEDOT:PSS/Xyl } \\
\text { on ESPVPANI }\end{array}$ & Spread coating & 26 & $50 \mathrm{um}$ & $\begin{array}{l}\text { Dark } \\
\text { nanowire } \\
\text { mat }\end{array}$ & Yes & 17 \\
\hline rGO scales & Spray coating & 1054 & $300 \mathrm{um}$ & Dark strip & No & 18 \\
\hline $\begin{array}{l}\text { AgNWs/rGO on } \\
\text { TPU }\end{array}$ & Spray coating & $4.40 \mathrm{E}+07$ & 74 um & Dark strip & No & 19 \\
\hline $\begin{array}{l}\text { Graphene nano } \\
\text { platelets }\end{array}$ & $\begin{array}{l}\text { Dip coating } \\
\text { silicone rubber }\end{array}$ & 10 & Bulk ->1cm & $\begin{array}{l}\text { Dark } \\
\text { Sponge }\end{array}$ & No & 20 \\
\hline $\begin{array}{l}\text { Braided } \\
\text { graphene belts }\end{array}$ & CVD graphene & $>175$ & $525 \mathrm{~nm}$ & Dark patch & No & 21 \\
\hline $\begin{array}{l}\text { AgNW/WPU- } \\
\text { MXene }\end{array}$ & $\begin{array}{l}\text { PU fibre dip } \\
\text { coating }\end{array}$ & $1.60 \mathrm{E}+07$ & & Dark strand & No & 22 \\
\hline $\begin{array}{l}\mathrm{Au} / \mathrm{Cu} / \mathrm{ZnO} / \mathrm{Pt} \\
\text { Thin-film }\end{array}$ & $\begin{array}{l}\text { Clean room } \\
\text { techniques }\end{array}$ & 18 & 100 um & $\begin{array}{l}\text { Transparent } \\
\text { gold pattern }\end{array}$ & Yes & 23 \\
\hline rGO/TPU & Ultrasonication & 79 & 200um & Dark Strip & No & 24 \\
\hline CNT & Blade coating & 1140 & 7.5um /300um & Transparent & No & 25 \\
\hline Nanographene & PECVD & 507 & & $\begin{array}{l}\text { Transparent } \\
\text { with gold } \\
\text { pads }\end{array}$ & No & 26 \\
\hline
\end{tabular}


An informed signed consent from the subject was obtained prior to the experiments. The fabricated sensors were based on Polydimethylsiloxane (PDMS) and Polyethylene terephthalate (PET) biocompatible platforms. The Author (VS) of the manuscript has used self as the subject for carrying out experiments with the wearable GLE sensor and GLE band. Therefore, approval from national or institutional ethics board/committee was not necessary for carrying out the reported experiments.

\section{S19. Abbreviations}

GO - Graphene Oxide

GLE - Graphene on Laser-patterned Electrodes

PVA - Poly(vinyl alcohol)

PMMA - Poly(methyl methacrylate)

CVD - Chemical Vapor Deposition

vdW - Van Der Waals

XRD - X-ray diffraction

XPS - X-ray photoelectron spectroscopy

FE-SEM - field emission scanning electron microscopy

BET - Brunauer-Emmett-Teller

BHJ - Barrett-Joyner-Halenda

TEM - Transmission Electron Microscopy

\section{S20. References:}

(1) Paredes, J. I.; Villar-Rodil, S.; Solís-Fernández, P.; Martínez-Alonso, A.; Tascón, J. M. D. Atomic Force and Scanning Tunneling Microscopy Imaging of Graphene Nanosheets Derived from Graphite Oxide. Langmuir 2009, 25 (10), 5957-5968. https://doi.org/10.1021/la804216z.

(2) Blanton, T. N.; Majumdar, D. Characterization of X-Ray Irradiated Graphene Oxide Coatings Using X-Ray Diffraction, X-Ray Photoelectron Spectroscopy, and Atomic Force Microscopy. Powder Diffr. 2013, 28 (2), 68-71. https://doi.org/10.1017/S0885715613000109.

(3) Goodman, P. Current and Future Uses of Gold in Electronics. Gold Bull. 2002, 35 (1), 21-26. https://doi.org/10.1007/BF03214833.

(4) Dong, X.; Huang, W.; Chen, P. In Situ Synthesis of Reduced Graphene Oxide and Gold Nanocomposites for Nanoelectronics and Biosensing. Nanoscale Res Lett 2010, 6 (1), 60. https://doi.org/10.1007/s11671-010-9806-8.

(5) Lewis, A. P.; Down, M. P.; Chianrabutra, C.; Jiang, L.; McBride, J. W.; Spearing, S. M. The Effect on Switching Lifetime of Chromium Adhesion Layers in Gold-Coated Electrical Contacts 
under Cold and Hot Switching Conditions. In 2013 IEEE 59th Holm Conference on Electrical Contacts (Holm 2013); 2013; pp 1-7. https://doi.org/10.1109/HOLM.2013.6651433.

(6) Li, J.; Sollami Delekta, S.; Zhang, P.; Yang, S.; Lohe, M. R.; Zhuang, X.; Feng, X.; Östling, M. Scalable Fabrication and Integration of Graphene Microsupercapacitors through Full Inkjet Printing. ACS Nano 2017, 11 (8), 8249-8256. https://doi.org/10.1021/acsnano.7b03354.

(7) Gaur, A. P. S.; Xiang, W.; Nepal, A.; Wright, J. P.; Chen, P.; Nagaraja, T.; Sigdel, S.; LaCroix, B.; Sorensen, C. M.; Das, S. R. Graphene Aerosol Gel Ink for Printing Micro-Supercapacitors. ACS Appl. Energy Mater. 2021, 4 (8), 7632-7641. https://doi.org/10.1021/acsaem.1c00919.

(8) Goh, G. L.; Zhang, H.; Chong, T. H.; Yeong, W. Y. 3D Printing of Multilayered and Multimaterial Electronics: A Review. Adv. Electron. Mater. n/a (n/a), 2100445. https://doi.org/10.1002/aelm.202100445.

(9) Goh, G. L.; Agarwala, S.; Yeong, W. Y. High Resolution Aerosol Jet Printing of Conductive Ink for Stretchable Electronics. NRF (Natl Research Foundation, S'pore) 2018. https://doi.org/10.25341/D4FS3W.

(10) Zhang, X.-W.; Pan, Y.; Zheng, Q.; Yi, X.-S. Time Dependence of Piezoresistance for the Conductor-Filled Polymer Composites. J. Polym. Sci. Part B Polym. Phys. 2000, 38 (21), 27392749. https://doi.org/10.1002/1099-0488(20001101)38:21<2739::AID-POLB40>3.0.CO;2-O.

(11) Souri, H.; Banerjee, H.; Jusufi, A.; Radacsi, N.; Stokes, A. A.; Park, I.; Sitti, M.; Amjadi, M. Wearable and Stretchable Strain Sensors: Materials, Sensing Mechanisms, and Applications. Adv. Intell. Syst. 2020, 2 (8), 2000039. https://doi.org/10.1002/aisy.202000039.

(12) Nakamura, A.; Hamanishi, T.; Kawakami, S.; Takeda, M. A Piezo-Resistive Graphene Strain Sensor with a Hollow Cylindrical Geometry. Mater. Sci. Eng. B 2017, 219, 20-27. https://doi.org/10.1016/j.mseb.2017.02.012.

(13) Huang, J.; Zeng, J.; Liang, B.; Wu, J.; Li, T.; Li, Q.; Feng, F.; Feng, Q.; Rood, M. J.; Yan, Z. Multi-Arch-Structured All-Carbon Aerogels with Superelasticity and High Fatigue Resistance as Wearable Sensors. ACS Appl. Mater. Interfaces 2020. https://doi.org/10.1021/acsami.0c01794.

(14) Liu, T.; Zhu, C.; Wu, W.; Liao, K.-N.; Gong, X.; Sun, Q.; Li, R. K. Y. Facilely Prepared Layerby-Layer Graphene Membrane-Based Pressure Sensor with High Sensitivity and Stability for Smart Wearable Devices. J. Mater. Sci. Technol. 2020, 45, 241-247. https://doi.org/10.1016/j.jmst.2019.11.014.

(15) Xu, M.; Qi, J.; Li, F.; Zhang, Y. Highly Stretchable Strain Sensors with Reduced Graphene Oxide Sensing Liquids for Wearable Electronics. Nanoscale 2018, 10 (11), 5264-5271. https://doi.org/10.1039/C7NR09022F.

(16) Han, Z.; Liu, L.; Zhang, J.; Han, Q.; Wang, K.; Song, H.; Wang, Z.; Jiao, Z.; Niu, S.; Ren, L. High-Performance Flexible Strain Sensor with Bio-Inspired Crack Arrays. Nanoscale 2018, 10 (32), 15178-15186. https://doi.org/10.1039/C8NR02514B.

(17) Ghosh, S. K.; Sinha, T. K.; Xie, M.; Bowen, C. R.; Garain, S.; Mahanty, B.; Roy, K.; Henkel, K.; Schmeißer, D.; Kim, J. K.; Mandal, D. Temperature-Pressure Hybrid Sensing All-Organic Stretchable Energy Harvester. ACS Appl. Electron. Mater. 2021, 3 (1), 248-259. https://doi.org/10.1021/acsaelm.0c00816.

(18) Yang, Y.-F.; Tao, L.-Q.; Pang, Y.; Tian, H.; Ju, Z.-Y.; Wu, X.-M.; Yang, Y.; Ren, T.-L. An Ultrasensitive Strain Sensor with a Wide Strain Range Based on Graphene Armour Scales. Nanoscale 2018, 10 (24), 11524-11530. https://doi.org/10.1039/C8NR02652A.

(19) Li, Y.; Wang, S.; Xiao, Z.; Yang, Y.; Deng, B.; Yin, B.; Ke, K.; Yang, M. Flexible TPU Strain Sensors with Tunable Sensitivity and Stretchability by Coupling AgNWs with RGO. J. Mater. Chem. C 2020, 8 (12), 4040-4048. https://doi.org/10.1039/D0TC00029A.

(20) Davoodi, E.; Montazerian, H.; Haghniaz, R.; Rashidi, A.; Ahadian, S.; Sheikhi, A.; Chen, J.; Khademhosseini, A.; Milani, A. S.; Hoorfar, M.; Toyserkani, E. 3D-Printed Ultra-Robust Surface-Doped Porous Silicone Sensors for Wearable Biomonitoring. ACS Nano 2020, 14 (2), 1520-1532. https://doi.org/10.1021/acsnano.9b06283.

(21) Li, Y.; He, T.; Shi, L.; Wang, R.; Sun, J. Strain Sensor with Both a Wide Sensing Range and High Sensitivity Based on Braided Graphene Belts. ACS Appl. Mater. Interfaces 2020, 12 (15), 17691-17698. https://doi.org/10.1021/acsami.9b21921. 
(22) Pu, J.-H.; Zhao, X.; Zha, X.-J.; Bai, L.; Ke, K.; Bao, R.-Y.; Liu, Z.-Y.; Yang, M.-B.; Yang, W. Multilayer Structured AgNW/WPU-MXene Fiber Strain Sensors with Ultrahigh Sensitivity and a Wide Operating Range for Wearable Monitoring and Healthcare. J. Mater. Chem. A 2019, 7 (26), 15913-15923. https://doi.org/10.1039/C9TA04352G.

(23) Hua, Q.; Sun, J.; Liu, H.; Bao, R.; Yu, R.; Zhai, J.; Pan, C.; Wang, Z. L. Skin-Inspired Highly Stretchable and Conformable Matrix Networks for Multifunctional Sensing. Nat. Commun. 2018, 9 (1). https://doi.org/10.1038/s41467-017-02685-9.

(24) Wang, Y.; Hao, J.; Huang, Z.; Zheng, G.; Dai, K.; Liu, C.; Shen, C. Flexible Electrically Resistive-Type Strain Sensors Based on Reduced Graphene Oxide-Decorated Electrospun Polymer Fibrous Mats for Human Motion Monitoring. Carbon 2018, 126, 360-371. https://doi.org/10.1016/j.carbon.2017.10.034.

(25) Nie, B.; Li, X.; Shao, J.; Li, X.; Tian, H.; Wang, D.; Zhang, Q.; Lu, B. Flexible and Transparent Strain Sensors with Embedded Multiwalled Carbon Nanotubes Meshes. ACS Appl. Mater. Interfaces 2017, 9 (46), 40681-40689. https://doi.org/10.1021/acsami.7b12987.

(26) Zhao, J.; He, C.; Yang, R.; Shi, Z.; Cheng, M.; Yang, W.; Xie, G.; Wang, D.; Shi, D.; Zhang, G. Ultra-Sensitive Strain Sensors Based on Piezoresistive Nanographene Films. Appl. Phys. Lett. 2012, 101 (6), 063112. https://doi.org/10.1063/1.4742331. 